\title{
Imagine being off-the-grid: Millennials' Perceptions of Digital-Free Travel
}

\author{
Christina Floros ${ }^{\mathrm{a}}$, Wenjie Cai ${ }^{\mathrm{a} *}$, Brad McKenna $^{\mathrm{b}}$ and Dimah Ajeeb $^{\mathrm{c}}$
}

${ }^{a}$ Department of Marketing, Events and Tourism, University of Greenwich, London, United

Kingdom; ${ }^{b}$ Norwich Business School, University of East Anglia, Norwich, United Kingdom;

${ }^{c}$ School of Architecture and Cities, University of Westminster, London, United Kingdom.

*University of Greenwich

London SE10 9LS

United Kingdom

Phone: +44 (0)2083 317845

Email:w.cai@greenwich.ac.uk

Christina Floros is a final year undergraduate student in BA Tourism Management at the Department of Marketing, Events and Tourism, University of Greenwich, UK.

Wenjie Cai, $\mathrm{PhD}$, is a senior lecturer in Tourism and Hospitality at the Department of Marketing, Events and Tourism, University of Greenwich, UK. Wenjie received his PhD in Tourism from the University of Surrey, UK. His main research interests include tourist behaviours, technology use, social inclusion and intercultural communication.

Brad McKenna, $\mathrm{PhD}$, is a lecturer in Information Systems at the University of East Anglia, UK. Brad received his $\mathrm{PhD}$ in Information Systems from the University of Auckland, New Zealand. His research interests focus on how people use information technology, in particular, virtual worlds, social media, and in tourism contexts.

Dimah Ajeeb, PhD Candidate, is a lecturer in Tourism and Urban and Regional Planning at the School of Architecture and Cities, University of Westminster, UK. Her research interests focus on tourism policy, governance, and planning, community-led tourism, architectural and urban design, urban and regional planning, decentralization, multi-level governance, and community-led regeneration. 


\section{Imagine being off-the-grid: Millennials' Perceptions of Digital-Free Travel}

The blurred boundaries between home and away facilitated by the ubiquitous connectivity have resulted in restlessness in private life, even on holiday. Disconnecting from technology on holiday could potentially contribute to travellers' psychological sustainability. This article aims to theorise the perceptions of millennials towards digital-free travel (DFT). We interviewed 17 millennials and applied the Unified Theory of Acceptance and Use of Technology (UTAUT) qualitatively to uncover deep insights into their perceptions.

Millennials in the research believe that DFT is beneficial for their well-being, but also have concerns regarding social expectations, technology dependence and environmental support. This article firstly contributes towards the psychological sustainability from the perspective of digital well-being in tourism. Second, the qualitative use of UTAUT in a technology disconnection setting is novel. Finally, the study contributes to the empirical understanding of DFT from the aspect of millennials' perceptions. The study proposes that mental "away" should be aligned with physical "away" by reducing technology use to achieve psychological sustainability on holiday.

Keywords: qualitative; UTAUT; millennials; perception; digital-free travel; psychological sustainability

\section{Introduction}

We are living in a ubiquitously connected world. Information technology (IT) has reconfigured time and space, social relations, and enabled individuals to be socially present while physically absent (Katz and Aakhus, 2002; Urry, 2002). The idea of "absent presence" (Gergen, 2002) has been expanded to the notion of "copresence" in the tourism literature (Hannam, Butler, \& Paris, 2014). Copresence, which is showing availability virtually and corporally, could lead to negative effects on proximate interactions such as lack of social interactions, experiences of others, or travellers' well-being (Ayeh, 2018). Neuhofer (2016) argued at the same time as transforming the travel experience, IT also acts as a role of value 
destruction by creating an "interference" that prevents tourists from engaging in multisensory embodied experiences.

In recent years, a growing number of studies have examined the dark side of smartphone usage by investigating its negative impacts on physical health (Xie, Szeto, Dai, \& Madeleine, 2016), and more significantly, psychological well-being (Fox and Moreland, 2015). The high dependence on mobile technology has resulted in smartphone addiction (Enez Darcin et al., 2016), fear of missing out (FoMO) (Elhai, Levine, Dvorak, \& Hall, 2016), and nomophobia (the fear of not being able to use mobile phone) (King et al., 2013). These result in various mental health issues such as anxiety, depression, low self-esteem, and techno-stress (Elhai, Dvorak, Levine, \& Hall, 2017; Sanders, Field, Diego, \& Kaplan, 2000; Scott, Valley, \& Simecka, 2017). In 2018, the Royal Society for Public Health launched two campaigns: Scroll Free September, and \#StatusofMind to draw public attention to the impact of mobile technology on mental health and well-being.

Millennials, as digital natives who grow up with technologies, experience the transformational power and consequences that IT brings to their professional and private lives. Influenced by technology at a very early stage, millennials develop solid skills for digital usage and demonstrate an increased need for consistent connectivity (Santos, Veiga, \& Águas, 2016). The dark side of technology discussed earlier, thus, has more significant impacts on millennials professionally and personally (Gore, Balasubramanian, \& Paris, 2019). Considering the symptoms of technology addiction (Turel, Serenko, \& Giles, 2011) and the severe implications on those affected, there is a growing need for a better understanding of technology addiction and potential solutions in various settings.

Before the era of IT, travel was largely associated with "away" and "escapism" from mundane everyday life (Preston-Whyte, 2004). Lehto (2013) emphasised that mentally distancing from daily routines and commitments is one key perceived restorative property of 
travel. Comparing with evenings after work and weekends, the physical distance of holiday facilitates the mental distance from everyday worries and contributes positively to travellers' well-being (de Bloom, Nawijn, Geurts, Kinnunen, \& Korpela, 2017). However, the involvement of mobile technology reconfigures physical and social proximity and enables a person's mediated presence (Zhao, 2003). As an integral part of the lifestyle, smartphones affect our travel experiences in various aspects, particularly for tech-savvy young professionals and students (Jamal, Habib, \& Khan, 2017). Tourists, especially millennials today, bring their daily lives on holiday by constantly engaging with their personal and professional commitments through mobile technology (Ayeh, 2018; White and White, 2007). The constant availability online has made tourists "en-framed" by their digital devices and unable to escape on holiday (Voase, 2018).

In a tourism, IT, and sustainability context, Gössling (2017) introduced the term "psychological sustainability" within the broad term of social sustainability. Psychological sustainability in this context suggests a critical understanding of technology use in tourism, and its impacts on digital well-being and mental health. Travellers' sustained psychological well-being plays a significant role in the global tourism system through relational and interdependent influences (Helne and Hirvilammi, 2015). This has been largely overlooked in sustainable tourism studies. A closer investigation of psychological sustainability is required to gain a deeper understanding of the role of IT in sustainability. Psychological sustainability focuses on the critical issues of travellers' mental well-being in relation to IT use on holidays such as glamorisation (Cohen and Gössling, 2015), social connectedness (Germann Molz, 2012), and competitive social status (Fox and Moreland, 2015). This study focuses on the impacts of social connectedness on psychological sustainability on holiday, in particular, investigating the potential role of digital-free tourism (DFT) as a means to foster social connections with travel companions, and distance from daily routines and stress. 
Digital disconnection research in the tourism context has developed from investigating negative emotions of forced disconnection in the technology dead zones (Dickinson, Hibbert, \& Filimonau, 2016; Paris, Berger, Rubin, \& Casson, 2015; Pearce and Gretzel, 2012) to advocating the benefits of a digital detox on holiday (Li, Pearce, \& Low, 2018; Neuhofer and Ladkin, 2017). The studies on DFT, especially the benefits of wellbeing, are still in early stages. Public media and Destination Management Organisations have shown large interests in this aspect. In the travel and hospitality industry, the concept of "digital detox", suggesting people take time off their smart devices to enjoy the holiday experience (Cai, McKenna, \& Waizenegger, 2019; Li, et al., 2018), has been increasingly popular, and largely adopted as a key element of wellness tourism (Smith and Puczkó, 2015). Although the benefits of DFT have been acknowledged, tech-savvy travellers, such as millennials still face challenges when considering partaking in DFT. Withdrawal symptoms related to technology disconnection have only recently been discussed in tourism contexts (Cai, McKenna, et al., 2019). However, there are examples in the IT literature (Clayton, Leshner, \& Almond, 2015; Kwon et al., 2013). Millennials who are suffering from constant connections can benefit largely from DFT. However, they might also be the demographic that finds it the most difficult to disconnect due to FoMO and nomophobia. Therefore, understanding millennials' perceptions of DFT will enrich the concept of psychological sustainability in IT and Tourism, and provide practical implications for interest parties of DFT. This study thus aims to explore the millennials' perceptions of DFT.

The Unified Theory of Acceptance and Use of Technology (UTAUT) (Venkatesh, Morris, Davis, \& Davis, 2003) is applied in the digitally-disconnected context in order to understand millennials' perceptions. Four key constructs of the UTAUT: performance expectancy, effort expectancy, social influences, and facilitating conditions originally designed to understand users' perception and use of new technology will be adapted and 
explored in the context of perceived DFT. Using semi-structured interviews, we provide a detailed account of millennials' perceptions. This article starts with a literature review of millennials as digital natives, DFT, and UTAUT, followed by the research design and data analysis. Next, the findings will be presented with narratives from our participants. The article will conclude with a discussion about how millennials evaluate the benefits and challenges of DFT.

\section{Millennials' IT use and psychological sustainability}

The literature offers a wide variety, yet controversial definitions of millennials. Different sectors in different contexts or geographies adopt marketing, services and practices relevant to their own definitions of millennials (see Dimock, 2019; Donnison, 2007; Washton and Brown, 2010). In this study, we define millennials as people born between 1981 and 2000 (Godelnik, 2017; Pendergast, 2010). Often characterised as “entitled, optimistic, civicminded and impatient" (DeVaney, 2015 p.13), however, this cohort are considered to be the best-educated and literate, most critical to governments' approaches and services provision, highest in cultural diversity, less charged in crimes or unpleasant social behaviours, and closer to their parents (Loda and Coleman, 2010).

The so-called "the digital or net generation" (Benckendorff and Moscardo, 2010), millennials have embraced technology at a very early stage, which results in a heightened need to be connected, and developed a solid skillset for technology usage (de Abreu e Silva, de Oña, \& Gasparovic, 2017). The leading adopters of smartphones are students aged 18-24 as well as young professionals 25-34 (Godelnik, 2017; Santos, et al., 2016). As digital natives, (Prensky, 2001), Cohen, Prayag, \& Moital (2014) suggested that millennials take technology for granted as part of their lives. Neuhofer (2016) further pointed out that 
millennials have come into the habit of being always connected. Wang, Xiang, \& Fesenmaier (2014) argued that a smartphone that serves as a "portable mini-computer" has become an integral aspect of millennial's life style to the point that it affects their travel experiences (Jamal, et al., 2017). Mobile phones enable millennials to have an "anywhere and anytime" connection, resulting in a feeling of dependence and inseparability (Kang and Jung, 2014; Lepp, Li, Barkley, \& Salehi-Esfahani, 2015).

IT plays a complex role in tourists' psychological sustainability. On one hand, the copresence enabled by mobile technology (Germann Molz, 2012) helps travellers to overcome loneliness (Ryan and Xenos, 2011) and emotionally integrate into their home relationships (White and White, 2007) while away. On the other hand, the negative consequences of copresence such as constant distractions from real-life connections (Turkle, 2017), a sense of unease (White and White, 2007), and destruction of travel experiences (Neuhofer, 2016) have been discussed in the literature. Mobile unreachability is essentially seen as a 'problemcausing' aspect as constant availability is rather an expectation nowadays. This high level of dependency reveals addictive smartphone usage behaviour (Cheever, Rosen, Carrier, \& Chavez, 2014; Reinecke et al., 2017) or triggers psychological factors such as nomophobia, FoMO, and increased negative experiences (Kneidinger-Müller, 2019). Characterised as "the desire to stay continually connected with what others are doing" (Przybylski, Murayama, DeHaan, \& Gladwell, 2013, p. 1841), FoMO is highly linked to problematic smartphone behaviours (Clayton, et al., 2015; Elhai, et al., 2016), particularly for the necessity to avoid the feeling of socially excluded (Gretzel, 2010) and to maintain popularity (Beyens, Frison, \& Eggermont, 2016). The FoMO phenomenon demonstrates the addictive behavioural pattern of mobile users. When the mobile phone is running out of battery, no signal is available, or simply the user is not able to use the phone; this creates the an "unsound angst" 
in FoMO users (Kang and Jung, 2014; Tams, Legoux, \& Léger, 2018).The resulted negative emotions and fear is called 'nomophobia'.

FoMO and nomophobia can cause a type of stress and anxiety, also known as technostress or decreased life-satisfaction (Cheever, et al., 2014). Constant availability of interaction and information exchange? may also lead to societal pressure (Kneidinger-Müller, 2019). Other consequences include negative impact on well-being, severe and lingering health problems as well as decreased productivity (Ayyagari, Grover, \& Purvis, 2011). Today's social expectations such as relentless availability and immediate responsiveness to texts and emails contribute directly to the rise of nomophobia (Kang and Jung, 2014).

\section{Digital-Free Travel}

Travel has long been romanticised as a way for tourists to escape their daily lives, even if in practice this is not always the case. Recently, the concept of home and away has been reconfigured with the increased mobility, and the ICT advancements in portable technology (White and White, 2007). The freedom to connect anytime and anywhere has shifted the norms towards constant availability, which leads to blurred boundaries between private and work times and results in both positive and negative impacts (Kim and Hollensbe, 2018; White and White, 2007). While technology offers various conveniences to travellers, it becomes increasingly difficult for them to switch off during their holidays (Ayeh, 2018).

The involvement of mobile technology detaches physical and social proximity and enables a person's mediated presence (Zhao, 2003) when he/she is on holiday. The concept of surveillance as a form of interpersonal and social relation has been discussed by Germann Molz (2006) in the tourism context. With the normalisation of copresence, travellers, on one hand, share their constant travel experiences online; on the other hand, are expected to be virtually available and visible to audiences' surveilling gaze. These collective expectations 
concerning availability and responsiveness have been explored by Mazmanian, Orlikowski, $\&$ Yates (2013). They found that the expected benefits of smartphones resulted in negative effects and diminished the employees' autonomy. In other words, employees find it difficult to disconnect from work commitment even in their private time. Despite considerable research on organisational studies focusing on the concept of disconnection from work, there has been a sparse focus in tourism research.

Whilst tourists benefit from the convenience of mobile technologies, the use of ICT may distract individuals from engaging with local and physical experiences (Tanti and Buhalis, 2016), for example, answering work-related emails, updating social media, and relying on Google Maps for directions and TripAdvisor for restaurants restricts travellers' experiences of exploring the area. By relying on technology, travellers are no longer able to explore the holiday destination independently and have fewer interactions with locals (Neuhofer, 2016).

Lehto and Lehto (2019) linked psychological sustainability with vacations by proposing a wellness-centred design framework to revisit the holiday as a public health resource. They argued that technology is one of the key factors leading to wellness imbalance, and travellers are seeking wellness enhancements on holiday. For people who are overloaded with technology use in everyday lives, a digital detox on holiday is essential. Positive outcomes of DFT, such as well-being and work-life balance have been discussed (see Dickinson, et al., 2016; Li, et al., 2018). However, self-motivated travellers willing to engage in a digital-free holiday face challenges from the expected professional and personal commitments, and many of them feel oppressive that they cannot escape from implied surveillance (Cooper, 2002).

In the academic literature, there is sparse empirical research looking at the disconnection of technology by choice during travel. Existing research focusses more on 
forced disconnection due to "technology dead-zones" (areas with no/poor connectivity) (Pearce and Gretzel, 2012). Considering the current hype about disconnected travelling, we address this gap and study travelling scenarios where people choose to disconnect and the implications of those disconnected experiences. Existing literature shows mixed outcomes on this topic. While some research reports positive outcomes such as therapeutic rehabilitation, improved work-life balance and positive lifestyle ( $\mathrm{Li}$, et al., 2018); others found negative reactions to the disconnected experiences. Going offline can lead to tensions, feelings of distress or anxiety (Germann Molz and Paris, 2015) as people lose the digital connection, access to information and knowledge, and the opportunity to communicate with colleagues, friends, and family.

Benefits of DFT such as reconnecting with physical environment and travel companions, and self-reflections were reported based on the empirical investigation of disconnected travellers' emotions (Cai, McKenna, et al., 2019). However, according to Dickinson, et al. (2016), some tourists cannot embrace the idea of disconnection due to the perceived negative emotions or experiences. Hence, there is often a paradox between people's desire to disconnect, and their ability to do so due to those negative emotions such as anxiety and tensions (O’Regan, 2008; Paris, et al., 2015). Tanti and Buhalis (2016) explored five consequences of being (dis)connected: 1) availability, 2) communication, 3) information obtainability, 4) time consumption, 5) supporting experience. However, these studies did not explore individuals' perceptions and understanding of DFT; most of the studies were conducted after the trip. Despite various calls for further investigations on digital-free travel experiences (Germann Molz and Paris, 2015; Neuhofer and Ladkin, 2017; Paris, et al., 2015), very few empirical studies have been conducted, especially on exploring how tech-savvy travellers perceive and weigh the benefits and inconveniences that digitalfree holiday will bring. A recent study by Cai, McKenna, et al. (2019) uncovered a deeper 
understanding of the emotional reactions to disconnecting on holiday but raised future research areas around the complex influences of professional and personal commitments which may prevent disconnection, as well as long-term impacts on well-being.

\section{Unified Theory of Acceptance and Use of Technology}

The Unified Theory of Acceptance and Use of Technology (UTAUT) (Venkatesh, et al., 2003), developed in the information systems discipline to understand an individuals' acceptance and use of technology (Venkatesh, Davis, \& Morris, 2007), has also been adopted in other fields (Venkatesh, Thong, \& Xu, 2016), for example in tourism (e.g. Fong, Lam, \& Law, 2017; San Martín and Herrero, 2012). UTAUT theorised the constructs of performance expectancy, effort expectancy, and social influence to influence behavioural intention to use technology, while behavioural intention and facilitating conditions determine technology use (Venkatesh, et al., 2016). Although originally developed for research at the individual level within organisational contexts, UTAUT in recent years also been adopted in consumer contexts. For example, Workman (2014) explored social media and smartphone applications to explore the use of navigation, weather information, and travel arrangements.

UTAUT has been used to explore individuals' acceptance and use of technology, which can include decisions not to use the technology. In this study, we aim to explore a different perspective of UTAUT, the intention of tourists to disconnect from technology while on holiday. By doing so, we can explore the same theoretical constructs from UTAUT, but from the perceptions of millennials who are used to using technology in their daily lives, to disconnect and partake in DFT. Therefore, our contextual use of UTAUT is the opposite side of technology adoption as we explore technology disconnection. As this is an exploratory study, we will explore the UTAUT constructs in a qualitative way, similar to other tourism research (McKenna, Cai, \& Tuunanen, 2018; tom Dieck and Jung, 2018), 
without testing the relationships between the constructs. In this way, we can have a deep understanding of how the main constructs of UTAUT might have an impact on perceptions of technology disconnection. We will briefly discuss the main UTAUT constructs next and argue how we think they can be applied in a disconnection context. We also classify the constructs as internal influences, where the perception is made individually by a person, or external, where the perception has some influences from other outside sources.

Performance expectancy is defined as "the degree to which an individual believes that using the system will help him or her to attain gains in job performance" (Venkatesh, et al., 2003 p.447). In our study, we consider this to be an internal influence, and we will explore the degree that millennials believe DFT can help to improve their well-being. Effort expectancy is defined as "the degree of ease associated with the use of the system" (Venkatesh, et al., 2003 p.450). In our study, we consider this to be an internal influence, and we will explore the perceived ease of disconnecting from technology while on holiday. Social influence is defined as "the degree to which an individual perceives that important others believe he or she should use the new system" (Venkatesh, et al., 2003 p.451). In our study, we consider this to be an external influence, and we will explore how external social factors may influence the perception of technology disconnection while on holiday. These three constructs influence the intention to disconnect. The final construct, facilitating conditions, influences actual disconnection behaviour and is defined as "the degree to which an individual believes that an organisational and technical infrastructure exists to support the use of the system" (Venkatesh, et al., 2003 p.453). In our study, we consider this to be an external influence, and we will explore how tourism infrastructure and physical elements such as public signage or availability of tourist information centres impact on the ability to disconnect. 


\section{Research Methods}

This study is underpinned by the interpretive paradigm to obtain a deep understanding of millennials' perceptions of DFT. Semi-structured interviews were conducted between January and March 2019 to gain a detailed account of participants' perceptions.

Homogeneous sampling technique with a focus on tech-savvy millennials was applied to select participants for this study to achieve an in-depth understanding of the researched group (Ritchie, Lewis, \& Elam, 2003). Two selection criteria were applied when choosing participants: millennials born between 1981 to 2000; and who use digital technologies daily. The selection criteria excluded those who are not digitally active and thus less influenced by DFT. Participants joined this study on a voluntary basis. Semi-structured interviews were designed in three main parts by investigating participants' relationship and perception towards daily technology use, reactions towards the idea of disconnecting from mobile technologies, and perceptions of DFT. Participants were asked to provide examples of how they felt when there was no Internet connection available or to give an illustration of their idea of what a DFT entails. A semi-structured approach allowed the researchers to explore a topic further. Participants were fully informed about the aim and objectives of the study and gave their consents before the interviews took place. In total, 17 face-to-face interviews were conducted in the UK when reaching the point of saturation, where no new themes or patterns emerged. Participant information is provided in table 1.

All interviews were transcribed and went through a two-stage thematic data analysis. Theoretical coding was applied in the first round. We applied an inductive approach by exploring the key patterns and themes from the interviews. We then applied provisional coding by using the four constructs from UTAUT: performance expectancy, effort 
expectancy, social influence and facilitating conditions to further categorise and refine themes and patterns from the first round.

\section{<TABLE 1 HERE>}

\section{Findings}

\section{Motivations and Perceived Benefits of DFT (Performance Expectancy)}

Negative perceptions of daily technology use

“To be honest, it's quite stressful because just seeing your phone you'd like to pick it up to check something" (Emille).

Many participants showed negative emotions towards constant connectivity afforded by digital technologies. "Well, I feel kind of annoyed that I have to be on it all the time now ...I don't want to be glued to a phone", although expressing negative perceptions towards her mobile phones, Krithika explained the nature of her job expecting her to be online constantly: "I miss the times where I didn't even know where my phone was, but now Ifeel a pressure to be on it all the time because of my profession, I feel like I need to be on it". The obligation to check the phone regularly creates a sense of 'weight' for Gaia, not only professionally, but also socially: "to be honest, I feel heavier because I feel kind of obliged to check my phone. That's why I delete some social network apps just because I want to prevent myself from going on social networks". Similarly, Bennet also emphasised that: "it's underestimated how much bad effect that Instagram and other social media is going to have if you're not aware of it, and it can lead to unnecessary stresses". Marcella also confirmed by stating: "you are always unconsciously comparing with others on social media".

Recently, the development of some smartphone operational systems allows users to keep track of their screen time. Participants reported that they used their mobile phones more than they actually needed. "Way more than I thought!" Noa discussed his screen time: "I just checked, and on average I spend 4 hours a day on my phone. And then maybe also 4 to 6 
hours a day on my laptop for work”. Similarly, Bennet tried to feel less guilty by explaining that part of screen time is for work: "now you can check the stats and I think it was like five hours, bad! The thing is I do research and stuff, in terms of art, I guess some of it is productive. It's still 5 hours a day, which is a lot of time". Regardless of leisure or work, most participants recognised the overuse of smartphones in their daily lives. The reconfigurations of space facilitated by mobile technology (Urry, 2002; White and White, 2007), resulted in blurred boundaries between personal and professional lives. This intrusion of work into the private life alarmed participants, and they were looking for a break from it. Perceived Benefits of DFT

"I think we need to remember how life without mobile phones, without social media, without being connected all the time was. And we think we are missing out if we don't have phones but the thing is we actually missing out on life when we have phones" (Gaia).

Having a mental distance from the constant connections, and being able to relax is one main perceived benefits of DFT shared by participants: "I guess I will start relaxing because I won't be occupied my mind with outside information, and I can really enjoy what I do on the holiday" (Simone). She further added: "you don't receive all the information, which I would say $50 \%$ is just not really useful from daily life, and you are overwhelmed by them". Although "might feel naked without it (smartphone)", Roxana perceived DFT as "relieving, liberating, and free". Noa also stated that: "not being dependent on your phone is such a relief...To me, it means that you can free your head and be way more open to everything happening around you".

Many participants relate positively to the concept of "digital detox": "I think it will be like a facial. When you do a facial, you feel clean, you feel fresh, you feel like almost new- 
born. I think it would be the same for DFT. And then also you empty your head with information because it's an overflow of information and you cannot store that all. So, I think you have to detox from your information, and then you separate from that" (Simon). Similarly, Roxana also valued the benefit of detox from DFT: "in a lot of cases, devices are very demanding, good to be free once in a while, like a rehab, retreat or cure". While Hannah considered DFT as a "reset button": "I think that having DFT is almost going back in time to kind of hit a reset button for yourself and to make sure that you're not completely dependent on your phone. I think it makes you probably feel a bit more grounded. I can imagine that".

Participants also reported that they will appreciate the surroundings more if they go on holiday without smartphones: "I will probably be more present at the activities and I wouldn't be so busy trying to get a good picture" (Rebekka). Emilie agreed with living in the present: "I will be more present, enjoy what I am doing without thinking about something else". Thuba explained how switching off enabled several opportunities: "when you disconnect from your phone, you can communicate more, you could spend more time with others, and more time with yourself too". Similarly, Noa said: "you would be so much more open to everything happening around you. You would talk to people more easily because you kind of have no choice. And also you go to places you didn't expect to go. It's a whole different experience".

Some participants consider DFT as a great opportunity for self-reflection, including the relationship with technology, and self. The idea of DFT reminds Krithika of her childhood: "it reminded me when I was a kid and I used to reflect my thoughts and everything". Marcella explains how DFT offers an opportunity to reconnect to the self: "you get this feeling of reconnecting with yourself and you realise that what other people are doing (on social media) doesn't really matter to your life". In addition, experienced DFT 
herself before, Marcella also perceived values of DFT to reflect on her relationship with technology: "it's really relieving because you get used to not looking at your phone very quickly ... you feel really more connected with what's around. It is really sad that you notice how everyone actually is attached (to their phones)".

Participants perceive DFT positively. Tired of disruptions caused by ubiquitous connectivity, they believe that being physically and digitally away is an opportunity for them to engage more with environmental surroundings, travel companions and locals, and facilitate chances of self-reflection. All these benefits, together along with being tired of overloaded technology use, strongly convince millennials DFT will contribute to their well-being.

\section{Digital-free tourist infrastructures (Facilitating Conditions)}

Facilitating conditions in this context understand how tourism infrastructure and environmental elements influence millennials' ability to disconnect on holiday. Today, the majority of tourism and hospitality businesses are going digital, as they presume their customers are digitally connected on holidays. Some participants who were planning to undertake DFT found it challenging to do so. Sam, who planned to disconnect for his trip in Slovenia, found it impossible: "booked a shuttle service from the airport to Ljubljana online, one day before my trip, they informed me that they will text me where to meet them on arrivals. They really did not consider people who want to disconnect or does not have a mobile phone". On his DFT trip in Vienna, Michael was advised by the hotel receptionist to book a ticket of Schönbrunn Palace online to avoid long queues: "I told them I do not have my mobile phone with me and asked if they can help me with the bookings, the staff showed me the PC for customer instead, I have no choice but to end my DFT".

Participants also reported that there are not enough facilities to support digital-free tourists. "There were no clear signs for us to get back from the train station, we had to ask 
some people on the street, but they pointed us in the wrong direction, we ended up having to cross the train track, phew! That was dangerous", Sam complained there were not enough clear signposts in Ely. Similarly, Jerrold could not find much about the bus information in Lucerne: "we cannot find any information about the bus, well, certainly you can find it online, but we do not have our phones with us. We ended up with missing our last bus, but we did not know". Michael reflected his unfamiliarity with alternative material affordances when looking for his hotel from the metro station: "I printed out two versions of the maps just in case, but I still got lost! I had to go to another hotel to ask for directions, and the staff also needed to check her phone to give me directions".

The nature of the destination affects travellers' confidences to conduct DFT. Participants reported that it is more challenging to disconnect when travelling in urban destinations: "I think it really depends where you stay though, because if you travel to some urban areas like London, New York. Paris, or Milan, you will be worried about getting lost" (Luca). Noa showed great interests in participating DFT, but not in the city: "you can't have any contact with people digitally. To meet up with someone is kind of impossible. And also, I use Google Maps so much that I really would get lost without it". On the other hand, participants tend to be more willing to disconnect in rural areas and the countryside. Without the worry of getting lost in the complicated transport system in the city, Noa believed that DFT in small towns affords more interactions: "in small towns, I prefer more human contact. I can then easily leave my phone somewhere without a problem", he reflected on his experiences: "I was on an island in Indonesia. There was no Internet and Wi-Fi. After 10 days, I felt so so good and I was way more in the moment. And human contact was way better".

Tourism facilities and the nature of destination play a fundamental role in enabling or preventing millennials from engaging with DFT. Many tourism providers are shifting their 
designs to meet the increasing demands of tech-savvy travellers but neglected experiences of users who do not use mobile technologies on holiday. It is particularly challenging for digital natives who are dealing with technology withdrawal. The perceived withdrawal symptoms are much stronger in urban destinations. The concerns are generally related to being unable to navigate in the complicated urban system because of over-dependence on technology. Participants feel more at ease about the idea of DFT in the countryside and rural destinations. The facilitating conditions of these destinations help participants to engage with nature, locals and themselves, which are key benefits they perceive in DFT.

\section{Social factors on DFT perceptions (Social Influences)}

Digital health and the dark side of technology as a current trend in the media have transformed people's understanding and perceptions of technology. Although many participants have not tried DFT, from the media's description, they perceived it with a positive image as a "meditative break" (Krithika) or "a practice where you get rid of all your electronic devices and live a humble and not connected life" (Luca). Marcella understood it as: "to detach from social devices or technological devices even for a short amount of time we'll see how bad, how it increases your benefits".

In the world of networked sociality, millennials perceived mobile technology as the key tool to maintain social relations: "it's a connection to the outside world. Gives you full information about what's happening worldwide, and immediate contact with your friends" (Simon). Gaia also emphasised the significant role her phone plays in her social lives: "being an international student obviously I have friends abroad and my phone and social media are basically the only way I have to communicate with them. So, I would lose a big part of communication if I don't have my phone. But also, with my friend here. If you don't have a phone with you, how can you arrange to meet up with them?" 
Moreover, ubiquitous connectivity makes it challenging for travellers to disconnect from their social networks due to professional and personal commitments. In other words, they are expected to be online constantly even though they are digitally away. Luca, although intrigued in DFT, did not want to miss out important work-related information:

“at some point, I get a sense of misbehaving because I need to stay on track and understand if actually, I'm not missing out any opportunities, especially I'm currently looking for internships and then graduate jobs and masters, so I don't actually want to lose out on things too much".

Also, in the constantly changing world, many millennials are afraid of falling behind. Thuba stated: "you know you can't totally disconnect, because things are always changing and moving, so you need to be aware of that". Krithika also responded to the importance for her to stay connected: "if I don't have my electronics with me, I feel I am falling behind. Things I need to be doing, and in relationships, I need to be maintaining my persona that I have to maintain online”. Marcella explained how FoMO prevents people from participating in DFT: "because you feel left out and you feel like there is a topic of discussion that is always linked to you, such as something happening on social media, or a video on YouTube, it's really like everything online is around you because all our lives are on the phone".

Social influences in DFT involves two parts. Firstly, travelling digitally-free is still a novel concept. Therefore, the positive influences of DFT are largely coming from the media instead of participants' social circles. Media, in this case, acts effectively to influence positively on millennials' perceptions of DFT. Secondly, social expectations from work and daily lives continuously put pressures on participants who want to be digitally-free on holiday. Emotions such as guilt and anxiety were developed from these social influences. 


\section{Perceptions of ease to disconnect (Effort Expectancy)}

Technology as norm

As digital natives, many participants took the technology for granted. Rebecca disclosed that she never thought about a life without technology: "I never think about it like oh my God I could use my phone, it's just something you take for granted”. Hannah also confirmed: "I think I kind of take it for granted. That is the default". She further explained that the existence of mobile phones has gone above its functionality: "I definitely noticed that I still have the urge to check something even though I don't carry a phone. I still miss having that physical thing around". Roxana agreed: "I think it is scary, but I think lots of us feel the same. The phone is kind of an extension of our body".

Participants revealed a strong reliance on technology. 'Safety' and 'filling the gap' have been the keyword mentioned by participants:

'If I'm out, I feel 'safer' with my phone, as I can find my way around using Google Maps, or order an uber when going out at night" (Nat).

“I honestly sometimes feel blank as I don't know how to fill the gaps of not using technology because whenever I want to space out, I grab my phone and go on Instagram, check stories and get lost in the loop" (Luca).

FoMO

"I think it's more just something that I'm used to now, somehow I'm probably conditioned to using my phone a lot more than I actually need it. And I think that if I were to go a few days without using it then I would say it feels like, a fear of missing out with other people especially like the social aspect of it" (Hannah).

Many participants shared the FoMO feeling as Hannah, with a result of technology dependence. Rebecka illustrated how the so-called phantom vibrations had been the 
consequence of excessive phone usage: "you know when you feel like you're getting a notification, but you don't. Then you check your phone just to see. That applies to me". Luca compared the IT addiction with the coffee and sugar addiction: "it was like literally an addiction to me. Even though I just checked social media, like 10-15 minutes ago, you know stories come out really quick, so it leaves me a feeling of being not content in what I'm doing. So, Ifeel the need to check, it's like when you haven't had coffee or sugar for a long time and like nicotine and get back to it. And then you feel like yes that's what I've missed out”. Because of FoMO, many participants self-diagnosed nomophobia: "I think a lot of people are addicted to their phones, it's just not necessarily categorised that way (nomophobia), uhm, it does not sound that healthy to me but then again, I agree" (Hannah). When perceiving not able to use her phone, Thuba described "half my world is gone".

When perceiving DFT, although the benefits of well-being were discussed by participants, many of them expressed their concerns and negative emotions. Annoyance and irritations were commonly expected withdrawal symptoms shared by participants. "It feels like I am in a cage", Krithika explained: "I won't be able to check my emails from work and then I can't watch anything. I'm usually always on my phone even when I'm cooking, I will go crazy”, Stephanie said: “maybe I'll use my friend's phone to look into my social media".

Although feeling positively towards DFT, participants perceived several barriers in terms of disconnecting on holiday. These concerns develop from their pressure of social expectations through ubiquitous connectivity (White and White, 2007) and strong digital dependence (Enez Darcin, et al., 2016) in their daily lives. Many participants found it difficult to fully commit to complete DFT, and suggested half DFT or by reducing technology use gradually: "I feel like going cold turkey may be a bit too much and unrealistic for the moment and I don't know how much that would actually help, but maybe a gradual reduction might help and be more effective" (Hannah). Although acknowledging the 
importance of DFT, Luca still wanted to take time to share his travel experiences through social media: "I enjoy living in the moment when I'm on holidays, but I also feel the need to somehow show the world through the social media".

\section{Discussion and Conclusion}

As digital natives, millennials are tired of constant connections (Gore, et al., 2019; Newport, 2019) and looking for engaging in the real sense of being "away" (Preston-Whyte, 2004) when on holiday. We found that millennials have relatively high levels of performance expectancy due to positive perceptions of DFT in relation to their mental well-being. Although the benefits and necessity of DFT have been fostered by media coverage as positive outcomes, there remain some barriers to DFT. These barriers arise from three main areas: 1) expected social influences such as personal and professional commitments, 2) unfriendly tourism infrastructure (facilitating conditions), and 3) a lack of confidence to disconnect due to FoMO and nomophobia (effort expectancy). Millennials value the importance of the concept of "disconnect to reconnect" and its contribution to psychological sustainability (Gössling, 2017). However, considering the negative emotions and concerns reported by participants, it is important to question the effectiveness of DFT to achieve well-being.

Based on the findings, we argue it is crucial to revisit the significance of the concept “away" (Preston-Whyte, 2004; White and White, 2007), as an essential contributor to psychological sustainability (Gössling, 2017). As a result of ubiquitous connectivity, the blurred boundaries between home and away (Kim and Hollensbe, 2018) have resulted in restlessness, even on holiday. We suggest that the mental "away" is as important as the physical "away" to enhance well-being through holidays. Technology plays a crucial role in mental "away"; we, therefore, encourage balanced levels of digital disconnection to detach home and away. This requires strong confidence of millennials to travel without the functionality of mobile technologies, as well as battling with their technology 
dependence/addictions on holidays (Enez Darcin, et al., 2016). Moreover, a shift in social expectations (Germann Molz, 2006; Kang and Jung, 2014) is required to support this home and away detachment. Millennials thus can enjoy the benefits of DFT and enhance their wellbeing without worrying about their social and work commitments. We also found that the increasing digitalisation of tourism and hospitality services (Buhalis and O'Connor, 2005) may also contribute to millennials' willingness to disconnect. Our participants reported their frustrations that service providers' shift towards digitalisation might hinder or prevent their needs for DFT as they were sometimes forced to reconnect to access these services.

This paper makes three contributions, firstly towards the psychological sustainability (Gössling, 2017) and digital well-being (Kneidinger-Müller, 2019) of tourists who desire to participate in DFT (Li, et al., 2018). Secondly, the qualitative use of UTAUT (Venkatesh, et al., 2003) in a technology disconnection setting. Thirdly, the study contributes to the empirical understanding of DFT from the aspect of millennials' perceptions.

This study contributes to the knowledge of the under-explored digital well-being in tourism. Although digital well-being has been critically discussed in the technology literature (Hill, Betts, \& Gardner, 2015; Sum, Mathews, Pourghasem, \& Hughes, 2008), this is one of the very first studies to discuss the issue in the tourism context. Also, this study empirically contributes to the understanding and critical discussion of IT in psychological sustainability (Gössling, 2017) by linking mental well-being with perceived technology (not) use on holiday. We propose that a mental "away" should be aligned with physical away by reducing technology use to achieve psychological sustainability on holiday.

Theoretically, this study contributes to UTAUT literature in two ways. Firstly, we have used the UTAUT variables individually from the original overall structural model and provided a deeper understanding of their nature qualitatively without looking at the relationships between the constructs. Although there are some examples of doing this in a 
tourism context (e.g. McKenna, et al., 2018; tom Dieck and Jung, 2018), such papers are still limited. Therefore, we have provided an in-depth qualitative analysis of UTAUT in a sustainable tourism setting.

In doing so, we also contribute to using UTAUT in a technology disconnection context. This is the opposite side of traditional UTAUT studies, which had explored the intentions to use technology in various contexts, i.e. when individuals previously did not use the technology and their perceptions towards using it. In our study, we have enriched UTAUT knowledge by exploring this dynamic in the opposite direction, from individuals who are used to using technologies in their daily lives, to their perceptions towards not using it within a tourism context. Although usage studies have dominated both technology fields and tourism fields (Cai, Richter, \& McKenna, 2019), the use of UTAUT in this manner is novel, and can provide understandings of technology from a different perspective. This approach of applying technology related theories in the opposite context if their original use was also recently achieved by Cai, McKenna, et al. (2019) who used affordances and emotions theories developed in technology literature to advance theoretical insights from a technology disconnection context. Therefore, similarly, we believe using theories in this manner can open new movements towards a critical use of technology and open research potential from a holistic perspective, i.e. from the full range of use and non-use settings.

Contextually, this study contributes to the emerging topic of DFT (Li, et al., 2018) with the focus on the segment of millennials, who are highly influenced by technologies in their daily lives (de Abreu e Silva, et al., 2017). By providing an investigation of their perceptions, the findings will provide useful insights for destination management organisations and tourism businesses to better tailor their strategies to engage with the increasing needs for DFT. Providers thus can focus more on promoting the benefits of DFT for well-being, and providing extra support to millennial customers to cope with their 
negative perceptions such as anxiety and frustrations in travel design, marketing and operations.

Several limitations were identified in this study. First, most participants are based in the UK; future research can explore in different geographical and cultural settings to investigate if culture plays a role in DFT perceptions. Second, the study has double the number of female than male participants. In this study we used UTAUT. Future research can apply other theories concerning perceptions in a DFT context. Moreover, future research can explore other aspects of disconnection and sustainable tourism in areas such as psychological impacts on tourists, social influences, environmental impacts, and economic effects through more in-depth critical discussions of IT. Future research can also compare the expected impacts of disconnection during travel with actual experiences. Researchers can also apply more technology-related theories from the opposite perspective, to gain deeper understandings of technology-related phenomena. Lastly, the ideas developed in this paper can be tested in quantitative studies.

\section{Declaration of Interests}

There are no interests to declare.

\section{References}

Ayeh, J. K. (2018). Distracted gaze: Problematic use of mobile technologies in vacation contexts. Tourism Management Perspectives, 26, pp. 31-38.

Ayyagari, R., Grover, V., \& Purvis, R. (2011). Technostress: technological antecedents and implications. MIS Quarterly, 35(4), pp. 831-858.

Benckendorff, P., \& Moscardo, G. (2010). Understanding Generation-Y tourists: managing the risk and change associated with a new emerging market. In P. Benckendorff, G. Moscardo \& D. Pendergast (Eds.), Tourism and Generation Y (pp. 38-46). Cambridge: CABI. 
Beyens, I., Frison, E., \& Eggermont, S. (2016). "I don't want to miss a thing”: Adolescents' fear of missing out and its relationship to adolescents' social needs, Facebook use, and Facebook related stress. Computers in Human Behavior, 64, pp. 1-8.

Buhalis, D., \& O'Connor, P. (2005). Information communication technology revolutionizing tourism. Tourism Recreation Research, 30(3), pp. 7-16.

Cai, W., McKenna, B., \& Waizenegger, L. (2019). Turning It Off: Emotions in Digital-Free Travel.

Cai, W., Richter, S., \& McKenna, B. (2019). Progress on technology use in tourism. Journal of Hospitality Tourism Technology

Cheever, N. A., Rosen, L. D., Carrier, L. M., \& Chavez, A. (2014). Out of sight is not out of mind: The impact of restricting wireless mobile device use on anxiety levels among low, moderate and high users. Computers in Human Behavior, 37, pp. 290-297.

Clayton, R. B., Leshner, G., \& Almond, A. (2015). The Extended iSelf: The Impact of iPhone Separation on Cognition, Emotion, and Physiology. Journal of Computer-Mediated Communication, 20(2), pp. 119-135.

Cohen, S. A., \& Gössling, S. (2015). A darker side of hypermobility. Environment and Planning A: Economy Space, 47(8), pp. 166-1679.

Cohen, S. A., Prayag, G., \& Moital, M. (2014). Consumer behaviour in tourism: Concepts, influences and opportunities. Current issues in Tourism, 17(10), pp. 872-909.

Cooper, G. (2002). The mutable mobile: social theory in the wireless world Wireless world (pp. 19-31): Springer.

de Abreu e Silva, J., de Oña, J., \& Gasparovic, S. (2017). The relation between travel behaviour, ICT usage and social networks. The design of a web based survey. Transportation Research Procedia, 24, pp. 515-522. Retrieved from http://www.sciencedirect.com/science/article/pii/S2352146517307895

de Bloom, J., Nawijn, J., Geurts, S., Kinnunen, U., \& Korpela, K. (2017). Holiday travel, staycations, and subjective well-being. Journal of Sustainable Tourism, 25(4), pp. 573-588.

DeVaney, S. A. (2015). Understanding the millennial generation. Journal of Financial Service Professionals, 69(6), pp. 11-14.

Dickinson, J. E., Hibbert, J. F., \& Filimonau, V. (2016). Mobile technology and the tourist experience: (Dis)connection at the campsite. Tourism Management, 57, pp. 193-201.

Dimock, M. (2019). Defining generations: Where Millennials end and Generation Z begins. 
Donnison, S. (2007). Unpacking the millennials: A cautionary tale for teacher education. Australian Journal of Teacher Education, 32(3), p 1.

Elhai, J. D., Dvorak, R. D., Levine, J. C., \& Hall, B. J. (2017). Problematic smartphone use: A conceptual overview and systematic review of relations with anxiety and depression psychopathology. Journal of Affective Disorders, 207, pp. 251-259.

Elhai, J. D., Levine, J. C., Dvorak, R. D., \& Hall, B. J. (2016). Fear of missing out, need for touch, anxiety and depression are related to problematic smartphone use. Computers in Human Behavior, 63, pp. 509-516.

Enez Darcin, A., Kose, S., Noyan, C. O., Nurmedov, S., Y1lmaz, O., \& Dilbaz, N. (2016). Smartphone addiction and its relationship with social anxiety and loneliness. Behaviour Information Technology, 35(7), pp. 520-525.

Fong, L. H. N., Lam, L. W., \& Law, R. (2017). How locus of control shapes intention to reuse mobile apps for making hotel reservations: evidence from Chinese consumers. Tourism Management, 61, pp. 331-342.

Fox, J., \& Moreland, J. (2015). The dark side of social networking sites: An exploration of the relational and psychological stressors associated with Facebook use and affordances. Computers in Human Behavior, 45, pp. 168-176.

Gergen, K. J. (2002). The challenge of absent presence. In J. E. Katz \& M. Aakhus (Eds.), Perpetual contact: Mobile communication, private talk, public performance (pp. 227). Cambridge: Cambridge University Press.

Germann Molz, J. (2006). 'Watch us wander': mobile surveillance and the surveillance of mobility. Environment Planning A, 38(2), pp. 377-393.

Germann Molz, J. (2012). Travel connections: Tourism, technology and togetherness in a mobile world London: Routledge.

Germann Molz, J., \& Paris, C. M. (2015). The Social Affordances of Flashpacking: Exploring the Mobility Nexus of Travel and Communication. Mobilities, 10(2), pp. 173-192.

Godelnik, R. (2017). Millennials and the sharing economy: Lessons from a 'buy nothing new, share everything month' project. Environmental Innovation and Societal Transitions, 23 , pp. 40-52.

Gore, S., Balasubramanian, S., \& Paris, C. M. (2019). Antecedents and Outcomes of Smartphone Usage Among Indian Millennial Travellers. Cham.

Gössling, S. (2017). Tourism, information technologies and sustainability: an exploratory review. Journal of Sustainable Tourism, 25(7), pp. 1024-1041. 
Gretzel, U. (2010). Travel in the network: Redirected gazes, ubiquitous connections and new frontiers. Post-global network and everyday life, pp. 41-58.

Hannam, K., Butler, G., \& Paris, C. M. (2014). Developments and key issues in tourism mobilities. Annals of Tourism Research, 44, pp. 171-185.

Helne, T., \& Hirvilammi, T. (2015). Wellbeing and Sustainability: A Relational Approach. Sustainable Development, 23(3), pp. 167-175.

Hill, R., Betts, L. R., \& Gardner, S. E. (2015). Older adults' experiences and perceptions of digital technology:(Dis) empowerment, wellbeing, and inclusion. Computers in Human Behavior, 48, pp. 415-423.

Jamal, S., Habib, M. A., \& Khan, N. A. (2017). Does the Use of Smartphone Influence Travel Outcome? An Investigation on the Determinants of the Impact of Smartphone Use on Vehicle Kilometres Travelled. Transportation Research Procedia, 25, pp. 2690-2704.

Kang, S., \& Jung, J. (2014). Mobile communication for human needs: A comparison of smartphone use between the US and Korea. Computers in Human Behavior, 35, pp. 376-387.

Katz, J. E., \& Aakhus, M. (Eds.). (2002). Perpetual contact: Mobile communication, private talk, public performance. Cambrdige: Cambridge University Press.

Kim, S., \& Hollensbe, E. (2018). When work comes home: technology-related pressure and home support. Human Resource Development International, 21(2), pp. 91-106.

King, A. L. S., Valença, A. M., Silva, A., Baczynski, T., Carvalho, M., \& Nardi, A. E. (2013). Nomophobia: Dependency on virtual environments or social phobia? Computers in Human Behavior, 29(1), pp. 140-144.

Kneidinger-Müller, B. (2019). When the smartphone goes offline: A factorial survey of smartphone users' experiences of mobile unavailability. Computers in Human Behavior, 98, pp. 1-10.

Kwon, M., Lee, J.-Y., Won, W.-Y., Park, J.-W., Min, J.-A., Hahn, C., . . Kim, D.-J. (2013). Development and validation of a smartphone addiction scale (SAS). PloS one, 8(2), p e56936.

Lehto, X. Y. (2013). Assessing the Perceived Restorative Qualities of Vacation Destinations. 52(3), pp. 325-339.

Lehto, X. Y., \& Lehto, M. R. (2019). Vacation as a Public Health Resource: Toward a Wellness-Centered Tourism Design Approach. O(0), p 1096348019849684. 
Lepp, A., Li, J., Barkley, J. E., \& Salehi-Esfahani, S. (2015). Exploring the relationships between college students' cell phone use, personality and leisure. Computers in Human Behavior, 43, pp. 210-219.

Li, J., Pearce, P. L., \& Low, D. (2018). Media representation of digital-free tourism: A critical discourse analysis. Tourism Management, 69, pp. 317-329.

Loda, M. D., \& Coleman, B. C. (2010). Adjusting Attitudes Using Traditional Media: Magazines Can Still Move Millennials. In P. Benckendorff, G. Moscardo \& D. Pendergast (Eds.), Tourism and Generation $Y$ (pp. 131-142). Wallingford: CABI.

Mazmanian, M., Orlikowski, W. J., \& Yates, J. (2013). The autonomy paradox: The implications of mobile email devices for knowledge professionals. Organization science, 24(5), pp. 1337-1357.

McKenna, B., Cai, W., \& Tuunanen, T. (2018). Technology enabled information services use in tourism: an ethnographic study of Chinese backpackers. Pacific Asia Journal of the Association for Information Systems, 10(4), pp. 37-64.

Neuhofer, B. (2016). Value co-creation and co-destruction in connected tourist experiences Information and communication technologies in tourism 2016 (pp. 779-792): Springer.

Neuhofer, B., \& Ladkin, A. (2017). (Dis)Connectivity in the Travel Context: Setting an Agenda for Research. Cham.

Newport, C. (2019). Digital Minimalism: On Living Better with Less Technology UK: Penguin.

O'Regan, M. (2008). Hypermobility in backpacker lifestyles: The emergence of the internet café. Tourism mobilities: Local-global connections, pp. 109-132.

Paris, C. M., Berger, E. A., Rubin, S., \& Casson, M. (2015). Disconnected and unplugged: experiences of technology induced anxieties and tensions while traveling Information and communication technologies in tourism 2015 (pp. 803-816): Springer.

Pearce, P. L., \& Gretzel, U. (2012). Tourism in Technology Dead Zones: Documenting Experiential Dimensions. International Journal of Tourism Sciences, 12(2), pp. 1-20.

Pendergast, D. (2010). Getting to know the Y Generation. In P. Benckendorff, G. Moscardo \& D. Pendergast (Eds.), Tourism and Generation $Y$ (pp. 85-97). Cambridge: CAB International.

Prensky, M. (2001). Digital natives, digital immigrants part 1. On the horizon, 9(5), pp. 1-6. 
Preston-Whyte, R. (2004). The beach as a liminal space. In A. Lew, C. M. Hall \& A. Williams (Eds.), The blackwell's tourism companion (pp. 349-359). Oxford: Blackwell.

Przybylski, A. K., Murayama, K., DeHaan, C. R., \& Gladwell, V. (2013). Motivational, emotional, and behavioral correlates of fear of missing out. Computers in Human Behavior, 29(4), pp. 1841-1848.

Reinecke, L., Aufenanger, S., Beutel, M. E., Dreier, M., Quiring, O., Stark, B., . . Müller, K. W. (2017). Digital stress over the life span: The effects of communication load and internet multitasking on perceived stress and psychological health impairments in a German probability sample. Media Psychology, 20(1), pp. 90-115.

Ritchie, J., Lewis, J., \& Elam, G. (2003). Designing and selecting samples London: Sage.

Ryan, T., \& Xenos, S. (2011). Who uses Facebook? An investigation into the relationship between the Big Five, shyness, narcissism, loneliness, and Facebook usage. Computers in Human Behavior, 27(5), pp. 1658-1664.

San Martín, H., \& Herrero, Á. (2012). Influence of the user's psychological factors on the online purchase intention in rural tourism: Integrating innovativeness to the UTAUT framework. Tourism Management, 33(2), pp. 341-350.

Sanders, C. E., Field, T. M., Diego, M., \& Kaplan, M. (2000). The relationship of Internet use to depression and social isolation among adolescents. Adolescence, 35(138), pp. 237-237.

Santos, M. C., Veiga, C., \& Águas, P. (2016). Tourism services: facing the challenge of new tourist profiles. Worldwide Hospitality Tourism Themes, 8(6), pp. 654-669.

Scott, D. A., Valley, B., \& Simecka, B. A. (2017). Mental Health Concerns in the Digital Age. [journal article]. International Journal of Mental Health Addiction, 15(3), pp. 604-613. doi:10.1007/s11469-016-9684-0

Smith, M., \& Puczkó, L. (2015). More than a special interest: defining and determining the demand for health tourism. Tourism Recreation Research, 40(2), pp. 205-219.

Sum, S., Mathews, M. R., Pourghasem, M., \& Hughes, I. (2008). Internet technology and social capital: How the Internet affects seniors' social capital and wellbeing. Journal of Computer-Mediated Communication, 14(1), pp. 202-220.

Tams, S., Legoux, R., \& Léger, P.-M. (2018). Smartphone withdrawal creates stress: A moderated mediation model of nomophobia, social threat, and phone withdrawal context. Computers in Human Behavior, 81, pp. 1-9. 
Tanti, A., \& Buhalis, D. (2016). Connectivity and the consequences of being (dis) connected Information and communication technologies in tourism 2016 (pp. 31-44): Springer.

tom Dieck, M. C., \& Jung, T. (2018). A theoretical model of mobile augmented reality acceptance in urban heritage tourism. Current Issues in Tourism, 21(2), pp. 154-174.

Turel, O., Serenko, A., \& Giles, P. (2011). Integrating technology addiction and use: An empirical investigation of online auction users. MIS quarterly, 35(4), pp. 1043-1061.

Turkle, S. (2017). Alone together: Why we expect more from technology and less from each other UK: Hachette

Urry, J. (2002). Mobility and proximity. Sociology, 36(2), pp. 255-274.

Venkatesh, V., Davis, F., \& Morris, M. G. (2007). Dead or alive? The development, trajectory and future of technology adoption research. Journal of the association for information systems, 8(4), p 1.

Venkatesh, V., Morris, M. G., Davis, G. B., \& Davis, F. D. (2003). User Acceptance of Information Technology: Toward a Unified View. MIS Quarterly, 27(3), pp. 425-478.

Venkatesh, V., Thong, J. Y., \& Xu, X. (2016). Unified theory of acceptance and use of technology: A synthesis and the road ahead. Journal of the association for information systems, 17(5), pp. 328-376.

Voase, R. (2018). Holidays under the hegemony of hyper-connectivity: getting away, but unable to escape? Leisure Studies, 37(4), pp. 384-395.

Wang, D., Xiang, Z., \& Fesenmaier, D. R. (2014). Adapting to the mobile world: A model of smartphone use. Annals of Tourism Research, 48, pp. 11-26.

Washton, R., \& Brown, R. (2010). Millennials in the US: Trends and opportunities surrounding Gen-Y adults Rockville: Packaged Facts.

White, N. R., \& White, P. B. (2007). Home and away: Tourists in a connected world. Annals of Tourism Research, 34(1), pp. 88-104.

Workman, M. (2014). New media and the changing face of information technology use: The importance of task pursuit, social influence, and experience. Computers in Human Behavior, 31, pp. 111-117.

Xie, Y., Szeto, G. P., Dai, J., \& Madeleine, P. J. E. (2016). A comparison of muscle activity in using touchscreen smartphone among young people with and without chronic neck-shoulder pain. 59(1), pp. 61-72.

Zhao, S. (2003). Toward a taxonomy of copresence. Presence: Teleoperators Virtual Environments, 12(5), pp. 445-455. 



\begin{tabular}{|l|l|l|l|}
\hline Participant & Male / Female & Age & Employment status \\
\hline Emille & Female & 34 & Professional \\
\hline Krithika & Female & 22 & Student \\
\hline Gaia & Female & 21 & Student \\
\hline Bennet & Male & 21 & Student \\
\hline Marcella & Female & 24 & Professional \\
\hline Noa & Female & 22 & Student \\
\hline Simone & Female & 35 & Professional \\
\hline Roxana & Female & 23 & Professional \\
\hline Hannah & Female & 21 & Professional \\
\hline Rebekka & Female & 22 & Student \\
\hline Thuba & Male & 25 & Professional \\
\hline Sam & Male & 28 & Professional \\
\hline Michael & Male & 35 & Professional \\
\hline Luca & Male & 21 & Professional \\
\hline Nathalie & Female & 24 & Professional \\
\hline Stephanie & Female & 23 & Professional \\
\hline Jerrold & Male & 26 & Student \\
\hline
\end{tabular}

Table 1: Participant information 